\title{
Nasal nitric oxide measurements for the screening of primary ciliary dyskinesia
}

\author{
T. Wodehouse*, S.A. Kharitonov*, I.S. Mackay", P.J. Barnes*, R. Wilson", P.J. Cole
}

Nasal nitric oxide measurements for the screening of primary ciliary dyskinesia. T. Wodehouse, S.A. Kharitonov, I.S. Mackay, P.J. Barnes, R. Wilson, P.J. Cole. (C) ERS Journals Ltd 2003.

ABSTRACT: Primary ciliary dyskinesia (PCD) presents to general practitioners with symptoms pertinent to a variety of specialists because of the involvement of ciliated epithelium in the upper/lower respiratory tract, ears, eyes and genital tract. There is no easy, reliable screening test for $\mathrm{PCD}$, and thus, the majority of patients remain undiagnosed. Nitric oxide (NO) is measurable in nasal air of normal subjects and found to be low in cystic fibrosis $(C F)$ and very low in PCD. Recently, it was suggested to play an important role in regulating ciliary motility. The aim of this study was to evaluate whether measurements of nasal NO could be used to screen for PCD.

Nasal NO was measured from the nasal cavity by a chemiluminescence analyser in subjects with PCD, healthy controls, CF, idiopathic bronchiectasis, Young's syndrome and lone sinusitis.

Nasal NO was significantly lower in PCD (64.0 \pm 36.6$)$ compared with normal controls (759 \pm 145.8$)$, idiopathic bronchiectasis (734 \pm 163.7$)$, CF (447.5 \pm 162.6$)$, lone sinusitis (1487 \pm 734$)$ and Young's syndrome (644 \pm 129.9$)$. Nasal NO was also significantly lower in PCD than CF patients.

Measurement of nasal nitric oxide may therefore be used clinically in various specialities to screen suspected patients for primary ciliary dyskinesia.

Eur Respir J 2003; 21: 43-47.
*Dept of Thoracic Medicine, Imperial College School of Medicine at National Heart \& Lung Institute, Dovehouse Street, ${ }^{\#}$ Nose Clinic at Royal Brompton Hospital, Sydney Street and "Host Defence Unit, Royal Brompton Hospital, Sydney Street, London, UK.

Correspondence: P.J. Cole, Royal Brompton Hospital, Sydney Street, London SW3 6NP, UK. Fax: 442074869166

E-mail: yrz87@dial.pipex.com

\section{Keywords: Cilia}

nasal nitric oxide measurements primary ciliary dyskinesia

Received: January 22002

Accepted after revision: August 62002
Primary ciliary dyskinesia (PCD) is thought to be an autosomal recessive condition in which abnormal or absent beating of cilia hinder normal mucociliary clearance, which may present at birth, in childhood or as an adult. The commonest presentations are in the upper and/or lower respiratory tracts, with mucus retention and recurrent infection, which may become chronic, but it may present in any organ in which the highly conserved structure of the cilium is represented (e.g. ciliated respiratory epithelium, sperm tail).

PCD, although uncommon, is underdiagnosed because of lack of a simple screening test, with patients having to be referred to the few specialised centres with equipment and expertise to measure ciliary beat frequency and ciliary ultrastructure. Hence, few patients benefit from available preventative therapy, and the clinical course is often stormy (e.g. with the development of bronchiectasis, and inappropriate ear, nose and throat procedures $[1,2])$ because the underlying cause is not identified.

GustafsSON et al. [3] first described nitric oxide (NO) in human exhaled air and later LUNDBERG and coworkers [4-6] demonstrated that most of the exhaled air of healthy subjects originates from the upper respiratory tract, with only a minor contribution from the lower airways. An elevated level of exhaled NO has been demonstrated in asthma, bronchiectasis or upper respiratory tract infections due to induction of NO synthases during airway inflammation [7-9] and is inhibited by glucocorticoids $[10,11]$. There are three known conditions with reduced airway NO concentrations: PCD, first demonstrated by LUNDBERG et al. [12] in four patients with Kartagener's syndrome that had negligible levels of nasal NO patients, and later by other groups $[13,14]$; cystic fibrosis $(\mathrm{CF})[15$, $16]$; and systemic sclerosis with pulmonary hypertension [17]. NO is thought to be involved in both the regulation of ciliary motility and host defence.

Nasal NO has been measured in patients with PCD and compared with healthy and relevant disease controls to determine whether nasal NO could be used as a screening test for PCD.

\section{Materials and methods}

\section{Subjects}

Forty-two patients diagnosed with PCD (16 males, 24 females) attending the Host Defence clinic at Royal Brompton Hospital, London, UK, were recruited. Mean age of the patients was $34.2 \pm 10.9 \mathrm{yrs}$. All subjects had a documented ciliary ultrastructural defect: 21 subjects had outer dynein arm deficiency, 12 had inner dynein arm deficiency, five had no dynein arms, two had a microtubular transposition and two had a radial spoke defect. All PCD patients were clinically stable at the time of enrolment and none 
had any evidence of an acute infective exacerbation, such as pyrexia, chest pain, increased shortness of breath or changes in sputum colour, consistency or volume or any other increase in symptoms.

Sixteen healthy nonsmoking control subjects (hospital staff) volunteered for this study. The mean age was $36.2 \pm 6.2$ yrs, five were male and 11 were female with no history of respiratory or cardiovascular disease. None were receiving any long-term medication. All controls had been free from upper respiratory tract infections for 4 weeks prior to the $\mathrm{NO}$ measurements.

Fifteen CF patients (eight females, seven males) who attended a CF clinic at Royal Brompton Hospital consecutively for annual review took part in the study, all having a proven diagnosis of $\mathrm{CF}$ previously confirmed by an abnormal sweat chloride excretion and determination of the genomic defect. Mean age of the $\mathrm{CF}$ patients was $22.4 \pm 4.5$ yrs. Patients with nasal polyposis were excluded.

Eighteen patients attending the ear, nose and throat (ENT) clinic consecutively (nine females and nine males) with chronic sinusitis of non-PCD origin were also recruited at Royal Brompton Hospital. Mean age was $45.3 \pm 15.4$ yrs. Patients with chronic sinusitis were defined as having two or more of the following symptoms: anosmia or hyposmia, nasal blockage or congestion (not due to polyps), posterior rhinorrhoea or headache for $>1 \mathrm{~h}$ on most days for 2 months or more [18]. All had been diagnosed by an ENT surgeon and verified by computed tomography (CT) scanning. All patients were being treated or had previously been treated for their symptoms with nasal sprays, either decongestants and/or topical corticosteroids. Seven of the patients had undergone previous anstrostomies but these had only been partially successful as the patients were still experiencing persistent symptoms. None of the subjects had any other respiratory or cardiovascular disease.

Twelve male patients attending the Host Defence clinic with Young's syndrome were recruited at the Royal Brompton Hospital. Mean age was $53.2 \pm 8.9$ yrs. Patients were suspected of having this syndrome if they presented with azoospermia, sinusitis and bronchiectasis, and had PCD and CF excluded as causes. This condition is of unknown aetiology, but may be associated with a history of pink disease (mercury poisoning) in infancy $[19,20]$.

Twenty patients (14 females, six males) attending the Host Defence clinic consecutively with idiopathic bronchiectasis that had been established radiologically by high-resolution CT scanning were recruited. Mean age was $46.8 \pm 14.2$ yrs. All 32 subjects had undergone previous ciliary beat frequency and ultrastructure assessment to exclude PCD and estimation of sweat chloride excretion to exclude $\mathrm{CF}$.

\section{Nasal nitric oxide measurements}

Nasal NO was measured by a chemiluminescence analyser (LR2000; Logan Research Ltd, Rochester, UK) sensitive to NO at concentrations from 1 to 5,000 parts per billion ( $p p b$ ) by volume, adapted for on-line recording of NO concentration. This feature obviates the need for collection in a reservoir, with its variable loss of reactive NO, and thus gives a greater sensitivity and reproducibility [21]. The chemiluminescence analyser operates over a wide range of ambient temperatures $\left(5-40^{\circ} \mathrm{C}\right)$ and relative humidity $(0-95 \%)$ without adverse effect on measurement accuracy. The analyser was calibrated daily using certified NO mixtures $(50 \mathrm{ppb})$ in nitrogen (BOC special gases, Guildford, UK).

Nasal NO was measured in subjects sitting with a Teflon tube inserted inside the nostril ensuring a tight seal. The subject was then asked to take a deep breath in, close their mouth and not exhale. The breath was held for a minimum of $30 \mathrm{~s}$ and the subjects were asked to perform three measurements, the mean of these measurements being taken as the level of $\mathrm{NO}$ in the nose. The absence of an increase in carbon dioxide $\left(\mathrm{CO}_{2}\right)$ whilst sampling nasal $\mathrm{NO}$ confirms soft palate closure and improves the reproducibility of the test. Ambient NO level was recorded before each manoeuvre. If subjects were unable to hold their breath or $\mathrm{CO}_{2}$ was demonstrated in the sample, they were excluded from the study. Patients who were disease controls were excluded if the presence of nasal polyps was detected. The method of NO measurement was based on the 1997 European Respiratory Society Guidelines [21]. This method was approved by the Royal Brompton Hospital Ethics Committee.

\section{Data analysis}

For comparisons between means a one-way analysis of variance was used to test the relationship between the levels of nasal NO and disease. When a statistical difference was found an unpaired t-test was used in a bivariable way to compare the different groups. A range also is used to describe nasal NO measurements. Results are expressed as the mean \pm sD. A p-value of $<0.05$ was considered significant.

\section{Results}

\section{Nasal nitric oxide measurements}

All patients and controls completed the study. Nasal NO was very low in patients with PCD $(64.0 \pm 36.6 \mathrm{ppb})$, compared with healthy controls $(759 \pm 145.8 \mathrm{ppb})$, and significantly lower $(\mathrm{p}<0.0001)$ than in all disease control groups (fig. 1): $\mathrm{CF}$ $(447.5 \pm 162.6 \mathrm{ppb})$, idiopathic bronchiectasis (734 \pm $163.7 \mathrm{ppb})$, lone sinusitis of non-PCD origin $(1,487 \pm$ $734 \mathrm{ppb})$, and Young's syndrome (644 $129.9 \mathrm{ppb})$. PCD nasal NO was significantly lower than CF values $(p<0.0001)$ (table 1$)$. Finally, there was no significant difference in the nasal NO concentrations in PCD patients with different types of ultrastructural defects (fig. 2). 


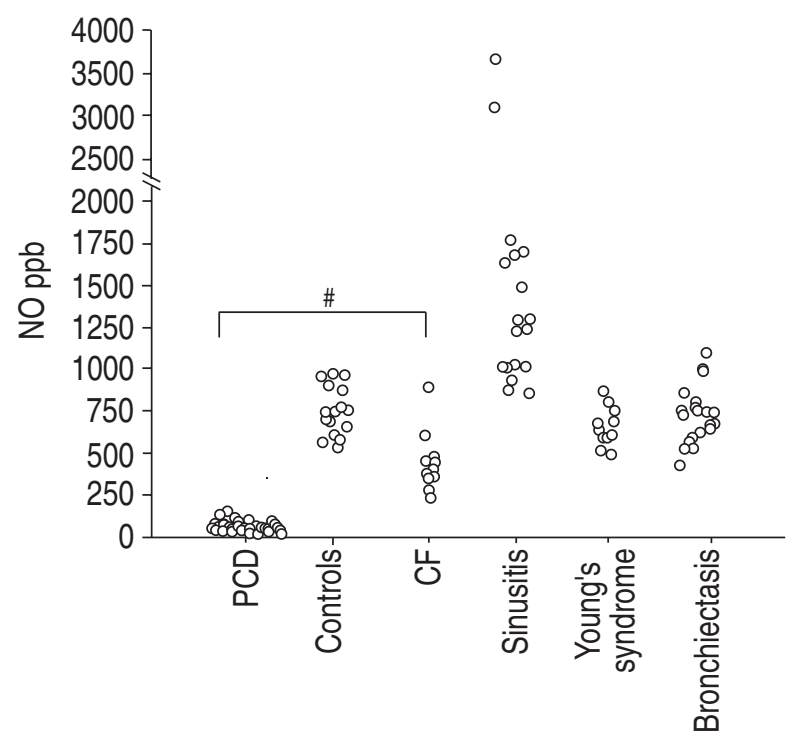

Fig. 1.-Nasal nitric oxide (NO) levels in subjects with primary ciliary dyskinesia (PCD; 17-180 parts per billion (ppb)) compared with healthy controls (543-976 ppb), and subjects with cystic fibrosis (CF; 241-896 ppb), sinusitis (862-3601 ppb), Young's syndrome $(330-1532 \mathrm{ppb})$ and bronchiectasis $(516-1098 \mathrm{ppb}){ }^{\#}$ : $\mathrm{p}<0.0001$.

Table 1. - Nasal nitric oxide (NO) in patients with primary ciliary dyskinesia (PCD) compared with healthy controls and patients with other infective respiratory conditions

\begin{tabular}{lcc}
\hline & \multicolumn{2}{c}{ Nasal NO (ppb) } \\
\cline { 2 - 3 } & Number & Mean \pm SD \\
\hline PCD & 40 & $65.7 \pm 36.6$ \\
Healthy controls & 16 & $759.1 \pm 145.8$ \\
Sinusitis & 18 & $1487 \pm 734$ \\
Young's Syndrome & 12 & $644 \pm 129.9$ \\
Bronchiectasis & 20 & $733.6 \pm 163.7$ \\
Cystic fibrosis & 15 & $448 \pm 162.6$ \\
\hline
\end{tabular}

ppb: parts per billion.

\section{Discussion}

Negligible levels of nasal NO in PCD were first identified by LUNDBERG et al. [12] and this were further investigated by other groups [13, 14]. In this study, it has been confirmed that a PCD cohort of well-defined ultrastructural defects have markedly lower levels of nasal NO compared with normal controls. It was also demonstrated that there is no overlap with other appropriate disease controls that exhibit similar upper respiratory symptoms as the PCD group, which differ from a previous study in which GRASEMANN et al. [13] compared PCD with CF. A nasal NO of $<200 \mathrm{ppb}$ would therefore indicate PCD and would thus appear suitable as a screening test for PCD.

There are several possible explanations for the low levels of nasal NO in PCD. It may be due to reduced or absent production of NO. There is growing evidence that NO plays a crucial role in the upregulation of ciliary motility [22-24], although the cellular

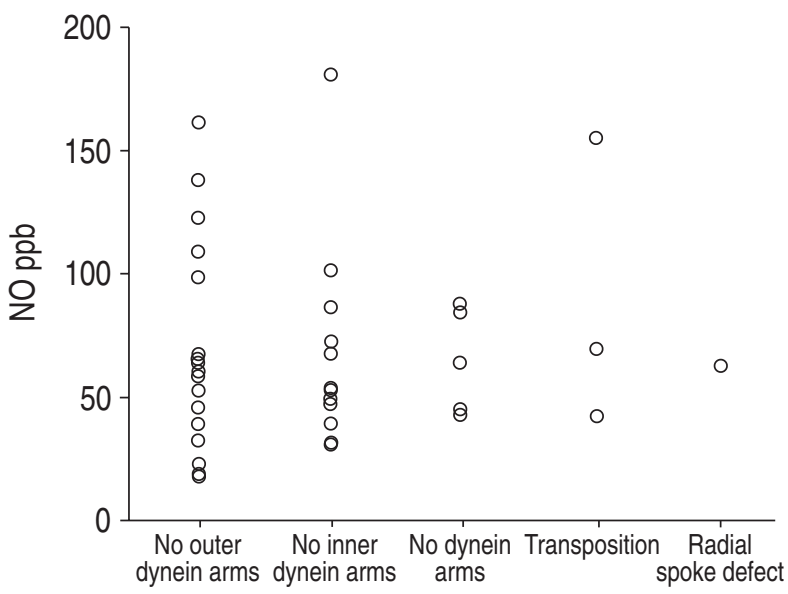

Fig. 2.-Mean nasal nitric oxide (NO) levels in different ultrastructural defects in subjects with primary ciliary dyskinesia. ppb: parts per billion.

control of ciliary function is not well understood. As the majority of respiratory epithelial cells are ciliated and contain nitric oxide synthase (NOS), it could be speculated that NO may modulate airway ciliary beating. If so, PCD might be expected to be closely related to impaired NO synthesis. If this were the case, stimulation of NO by NO donors, for example L-arginine substrates, could be of benefit in the treatment of this condition. The authors have recently demonstrated an increase in nasal mucociliary clearance and nasal NO in a small group of patients with PCD inhaling nebulised arginine [25], but it remains to be determined whether repeated short-term stimulation of NO production would be able to sustain adequate mucociliary clearance in the long-term treatment of patients with PCD. In another study, a small protein-designated protein inhibitor of neuronal NOS (PIN) was identified as a component of Chlamydomonas flagellar dynein $(90 \%$ homology with human proteins) and has been implicated as a regulator of neuronal NOS [26, 27], suggesting another possible relationship between dynein/cilia and NO regulation.

Recent work by MENG et al. [28] demonstrated that there is a negligible amount of NOS in bronchial epithelium of $\mathrm{CF}$ lung. Nasal NO measurements are found to be low in CF [16] compared with healthy controls, but not nearly as low as in PCD patients. Lack of NOS may also account for the negligible NO in PCD patients, which is a possibility that needs to be investigated.

In this study, there was no overlap of nasal measurements between PCD and other disease controls, most notably between PCD and CF, however, the presence of nasal polyps were excluded from this study. Arnal et al. [29] demonstrated that nasal NO concentrations in nonallergic patients with nasal polyposis were significantly decreased compared with controls and a correlation was found between the degree of obstruction of the paranasal sinuses and nasal NO measurements. Recently, HADFIELD et al. [30] reported that $37 \%$ of $211 \mathrm{CF}$ patients had significant nasal polyposis [30]. It would therefore seem reasonable to suggest that polyposis in CF may 
account for low measurements in some cases. As there was no overlap with other disease controls, this screening test for PCD appears to be $100 \%$ sensitive and specific. Other authors have demonstrated high concentrations of the NO metabolites nitrate and nitrite in CF airway secretions. In vitro studies have shown that superoxide anion release from activated polymorphonuclear neutrophils reduces airway epithelial cell-derived NO by forming nitrate [31]. This suggests that airway $\mathrm{NO}$ in $\mathrm{CF}$ could be decreased by degradation in airway fluids and this needs to be investigated in PCD

The authors conclude that nasal nitric oxide measurement is a simple noninvasive screening test for primary ciliary dyskinesia. However, the technique of measuring nitric oxide does require a certain level of expertise and the availability of the equipment used is not currently widespread, but with the heightened interest of using nitric oxide as a measurement of inflammation in asthma and other diseases [32], more centres are purchasing the equipment. This method does not replace the use of ciliary beat assessment on nasal brushing or biopsy to confirm the diagnosis and elucidate its ultrastructural nature. Furthermore, the expertise for assessment of ciliary beat frequency and electron microscopy is only available at a few specialised centres and therefore the diagnosis is not even considered in many patients presenting with upper and lower respiratory problems [1]. Thus, primary ciliary dyskinesia is underdiagnosed and appropriate preventative and symptomatic treatment may be denied in these patients.

Acknowledgement. The authors are grateful to D. Geddes for giving permission to include his cystic fibrosis patients in the study and $\mathrm{S}$. Meah for technical assistance.

\section{References}

1. Bush A, Cole PJ, Hariri M, et al. Primary ciliary dyskinesia: diagnosis and standards of care. Eur Respir J 1998; 12: 982-988.

2. Hadfield PJ, Rowe-Jones JM, Bush A, Mackay IS. Treatment of otitis media effusion in children with primary ciliary dyskinesia. Clin Otolaryngol 1997; 22: 302-306.

3. Gustafsson LE, Leone AM, Persson M-G, Wiklund NP, Moncada S. Endogenous nitric oxide is present in the exhaled air of rabbits, guinea pigs and humans. Biochem Biophys Res Comm 1991; 181: 852-857.

4. Alving K, Weitzberg E, Lundberg JM. Increased amount of nitric oxide in exhaled air of asthmatics. Eur Respir J 1993; 6: 1268-1270.

5. Lundberg J, Rinder J, Weitzberg E, Lundberg J, Alving K. Nasally exhaled nitric oxide originates mainly in the paranasal sinuses. Acta Physiol Scand 1994; 152: 431-432.

6. Lundberg JON, Farkas-Szallasi T, Weitzberg E, et al. High nitric oxide production in human paranasal sinuses. Nature Med 1995; 1: 370-373.

7. Kharitonov SA, Yates D, Robbins RA, Logan Sinclair R, Shinebourne EA, Barnes PJ. Increased nitric oxide in exhaled air of asthmatic patients. Lancet 1994; 343: 133-135.

8. Kharitonov SA, Wells AU, O'Conner B, Hansell D, Cole PJ, Barnes PJ. Elevated levels of exhaled nitric oxide in bronchiectasis. Am J Respir Crit Care Med 1995; 151: 1889-1893.

9. Kharitonov SA, Yates D, Barnes PJ. Increased nitric oxide in exhaled air of normal human subjects with upper respiratory tract infections. Eur Respir J 1995; 8: 295-297.

10. Kharitonov SA, Yates DH, Barnes PJ. Inhaled glucocorticoids decrease nitric oxide in exhaled air of asthmatic patients. Am J Respir Crit Care Med 1996; 153: $454-457$.

11. Jatakanon A, Lim S, Chung KF, Barnes PJ. An inhaled steroid improves markers of airway inflammation in patients with mild asthma. Eur Respir J 1998; 12: $1084-1088$.

12. Lundberg JON, Weitzberg E, Nordvall SL, Kuylenstierna R, Lundberg JM, Alving K. Primarily nasal origin of exhaled nitric oxide and absence in Kartagener's syndrome. Eur Respir J 1994; 7: 15011504.

13. Grasemann H, Gartig SS, Weisemann HG, Teschler H, Konietzko N, Ratjen F. Effect of L-arginine infusion on airway NO in cystic fibrosis and primary ciliary dyskinesia syndrome. Eur Respir J 1999; 13: 114-118.

14. Karadag B, James AJ, Gultekin E, Wilson NM, Bush A. Nasal and lower airway level of nitric oxide in children with primary ciliary dyskinesia. Eur Respir $J$ 1999; 13: 1402-1405.

15. Balfour-Lyn I, Laverty MA, Dinwiddle R. Reduced upper airway nitric oxide in cystic fibrosis. Arch Dis Child 1996; 75: 319-322.

16. Grasemann H, Michler E, Wallot M, Ratjen F. Decreased concentrations of exhaled nitric oxide (NO) in patients with cystic fibrosis. Ped Pulmonol 1997; 24: 173-177.

17. Kharitonov SA, Cailes JB, Black CM, du Bois RM, Barnes PJ. Decreased nitric oxide in the exhaled air of patients with systemic sclerosis with pulmonary hypertension. Thorax 1997; 52: 1051-1055.

18. Lund VJ, Mackay IS. Staging in rhinosinusitis. Rhinology 1993; 31: 183-184.

19. Hendry WF, A'Hern RP, Cole PJ. Was Young's syndrome caused by exposure to mercury in childhood? BMJ 1993; 307: 1579-1582.

20. Warkany J, Hubbard DM. Mercury in the urine of children with acrodymia. Lancet 1948; i: 829-830.

21. Kharitonov S, Alving K, Barnes P. Exhaled and nasal nitric oxide measurements: recommendations. Eur Respir J 1997; 10: 1683-1693.

22. Jain B, Rubinstein I, Robbins RA, Sisson J. TNF- $\alpha$ and IL-1 $\beta$ upregulate nitric oxide-dependent ciliary motility in bovine airway epithelium. Am Physiol Soc 1995; 268: L911-L917.

23. Jain B, Rubistein I, Robbins RA, Leise KL, Sisson JH. Modulation of airway epithelial cell ciliary beat frequency by nitric oxide. Biochem Biophys Res Comm 1993; 191: 83-88.

24. Sisson JH. Ethanol stimulates apparent nitric oxide-dependent ciliary beat frequency in bovine airway epithelial cells. Am Physiol Soc 1995; 268: L596-L600.

25. Loukides S, Kharitonov S, Wodehouse T, Cole PJ, Barnes PJ. Effect of arginine on mucociliary function in primary ciliary dyskinesia. Lancet 1998; 352: 371-372. 
26. Jaffrey SR, Snyder SH. PIN: An associated protein inhibitor of neuronal nitric oxide synthase. Science 1996; 274: 774-777.

27. Benashski SE, Harrison A, Patel-King RS, King SM. Dimerization of the highly conserved light chain shared by dynein and myosin. J Biol Chem 1997; 272: 20929-20935.

28. Meng D-H, Springall DR, Bishop AE, et al. Lack of inducible nitric oxide synthase in bronchial epithelium: a possible mechanism of susceptibility to infection in cystic fibrosis. J Pathol 1998; 184: 323-331.
29. Arnal JF, Flores P, Rami J, et al. Nasal nitric oxide concentration in paranasal sinus inflammatory diseases. Eur Respir J 1999; 13: 307-312.

30. Hadfield PJ, Rowe-Jones JM, Mackay IS. The prevalence of nasal polyps in adults with cystic fibrosis. Clin Otolaryngol 2000; 25: 19-22.

31. Jones KL, Bryan TW, Jinkins PA, et al. Superoxide release from neutrophils causes a reduction in nitric oxide gas. Am J Physiol 1998; 275: 1120-1126.

32. Kharitonov SA, Barnes PJ. Clinical aspects of exhaled nitric oxide. Eur Respir J 2000; 16: 781-792. 